\title{
Транспозиция личных форм и синтаксическая синонимия на материале неопределенно-личных предложений в русском языке
}

\author{
NAM HYE HYUN \\ Yonsei University, Yonsei-ro 50, Seodaemun-gu, Seoul, 120-749 Republic of Korea \\ E-mail: zean01@yonsei.ac.kr
}

(Received: 9 March 2018; accepted: 27 June 2018)

\begin{abstract}
The present paper considers the transposition of grammatical forms as a source of semantic derivation and a mechanism of syntactic synonymy. In particular, the author deals with the transposition of third-person plural forms in indefinite-personal sentences as well as their limitations in syntactic synonymy. Third-person plural forms are characterized by a significant referential variety. According to the referential variation of third-person plural forms, indefinite-personal sentences create synonymous relations with definite-personal sentences, passive sentences and generalized personal sentences.

Keywords: transposition, syntactic synonymy, indefinite-personal sentences, third-person plural forms, Russian
\end{abstract}

\section{1. Вводное слово}

Многогранность каждого явления внеязыковой реальности позволяет воспринимать и отражать его в языке с разных сторон, в различных отношениях, акцентируя внимание на каком-либо аспекте. Вопрос о возможности отражения одного и того же факта действительности различными языковыми средствами тесно связан с синонимией, в частности, нас интересует синтаксическая синонимия. Речь идет о том, когда одна внеязыковая ситуация может быть выражена несколькими предложениями, оформленными по разным структурам. Русский язык располагает огромным запасом синтаксических синонимов, то есть параллельных оборотов речи, которые различаются тонкими оттенками значений и могут в некоторых случаях заменять друг друга. В силу этого вопрос синтаксической синонимии является особенно актуальным для русского языка.

Синтаксическая синонимия как лингвистическое явление имеет давнюю традицию изучения как в зарубежной, так и в русской лингвистике. Термин «синтаксические синонимы» впервые был употреблен А. М. Пешковским, которого, прежде всего, интересовало то, какими языковыми средствами может быть выражена одна и та же мысль. Он делил грамматические синонимы на две группы: морфологические и синтаксические. К синтаксическим синонимам А. М. Пешковский относит различные случаи сближения по значению всевозможных грамматических форм (времен, наклонений), различные 
схемы построения предложения, предлоги и союзы, а также возможность замены имени существительного местоимением. В связи с многообразием синтаксической синонимии исследователь замечает, что стилистические возможности в синтаксисе гораздо многообразнее и значительнее, чем в морфологии (ПЕшковский 1930: 154).

В дальнейшем идея о синтаксической синонимии получила развитие в работах таких ученых, как Г. И. Рихтер, А. Н. Гвоздев, В. Н. Ярцева, И. И. Ревзина, И. И. Ковтунова, В. П. Сухотин, Е. М. Галкина-Федорук, Г. А. Золотова и др. По мнению Е. М. Галкиной-Федорук, синтаксическими синонимами являются такие конструкции, в которых содержится тождественное общесмысловое значение, создаваемое словами, лексически близкими по значению, выполняющими одинаковую функцию. Такие конструкции структурно различно организованы, однако способны замещать одна другую, например, в словосочетаниях: отцуовский дом - дом отцุа; человек с кривым носом кривоносый человек... (ГАЛКИНА-ФЕДОРук 1958: 8).

В свою очередь, Г. А. Золотова интерпретирует понятие «синоним» с точки зрения инвариантного подхода. На взгляд автора, в качестве постоянного признака предложения, на котором держатся отношения инвариантной модели к вариантным и вариантных моделей между собой, выступает типовое значение предложения. Изменение синтаксических форм компонентов модели в рамках того же значения составляет сущность синонимических преобразований предложения. В предложениях Мальчик читает стихи Стихи читаются мальчиком - Чтение стихов мальчиком отражается одно типовое содержание: отношение между деятелем, действием и объектом, на который направлено действие (ЗолотовА 1973: 25-26, 226). Наиболее широко распространенными критериями синтаксической синонимии являются общие синтаксические отношения, общее содержание и разноструктурность (ЧулАнова 2009: 8, Nagy 2009: 314).

В западной лингвистике вопросом синтаксической синонимии занимались, в основном, в плане трансформации. В трансформационной грамматике, основателем которой является Н. Хомский, выдвигается тезис о смысловой эквивалентности предложений, находящихся в трансформационных отношениях. При этом важно различать поверхностную и глубинную структуру. Поверхностная структура полностью задает фонетическую интерпретацию, а глубинная структура выражает те грамматические функции, которые играют роль в процессе семантической интерпретации. В этом плане синтаксические синонимы - это предложения, имеющие разные поверхностные структуры, но общую глубинную структуру.

Итак, исходя из предыдущих исследований, можно сделать вывод о том, что синтаксические синонимы - это такие конструкции, которые имеют тождественное смысловое значение, но различаются оттенками значения, обусловленными их разноструктурностью. Поэтому выбор одного из синонимичных средств связан с позицией говорящего, его определенным взглядом на ситуацию. 
Несмотря на приведенные исследования, многие ученые указывают, что эта область исследований является одной из наименее изученных в грамматике. Не раскрыта сущность функционирования синтаксической синонимии, и также не выявлен механизм возникновения структурно-семантических различий между конструкциями, вступающими в синонимичные отношения. ${ }^{1}$

Мы считаем, что при изучении синтаксической синонимии нужен принципиально такой же подход, как к лексической синонимии. Лексическая синонимия является результатом семантической деривации, возникающей вследствие употребления лексем в несвойственном им значении. Подобно этому, синтаксическая синонимия связана с транспозицией компонентов, составляющих конструкции, т. е. их употреблением в несобственном значении. Как будет представлено далее, транспозиция грамматических форм расширяет номинативные возможности языка и создает синонимичные отношения на разных уровнях языка и тем самым становится важным стилистическим ресурсом языка (Ремчукова 2000: 79).

В данной работе объектом рассмотрения являются неопределенно-личные предложения. Это, как правило, бесподлежащные предложения с глаголом-сказуемым в форме 3 л. мн. ч. Неопределенно-личные предложения в русском языке более употребительны по сравнению с другими славянскими и неславянскими европейскими языками (см. МАPOEвич 1993, SIEWERSKAРAPASTATHI 2011, Князев 2015: 148). Они составляют весомую часть синтаксических конструкций с неназванным субъектом, которые, наряду с безличными оборотами, так характерны для русского языка. Ведь по наблюдениям ученых, русский язык - в большей мере, чем английский - сохранил «рудименты» дономинального синтаксиса (НЕКРАСовА 2014: 103).

При рассмотрении синтаксической синонимии неопределенно-личных предложений мы будем исходить из транспозиции форм 3 л. мн. ч. Итак, во второй части работы коротко обсуждается транспозиция личных форм, а в третьей части рассматривается синтаксическая синонимия неопределенноличных предложений путем анализа референциальных свойств форм 3 л. мн. ч. В заключительной части обобщаются все высказанные положения.

\section{2. Транспозиция личных форм}

Термин «транспозиция» (transposition) определяется как использование одной языковой формы в функции другой формы - ее противочлена в парадигматическом ряду (ЛЭС 1990: 519). ${ }^{2}$ Например, транспозиция времени использование глагольных форм настоящего времени вместо прошедшего

${ }^{1} \mathrm{O}$ различиях как обязательном свойстве синонимичных явлений в языке Ф. де Соссюр пишет, что обладая одинаковой значимостью (общим ядром значения), синонимы различаются в структурном отношении и передают дополнительные оттенки (СоссюР 1977: 114-117).

${ }^{2} \mathrm{~B}$ более узком смысле транспозиция обозначает перевод слова из одной части речи в другую или его употребление в функции другой части речи. 
или будущего; транспозиция наклонений - употребление императива в значении индикатива или условного наклонения; транспозиция коммуникативных типов предложения - употребление вопросительного предложения в значении побудительного и др.

(1) Завтра я еду в Москву.

(2) Возвращаюсь вчера с вокзала домой, иду темной улицей. Вдруг вижу: у фонаря что-то белеет.

(3) А у Аннушки масло возьми да и разлейся.

(4) Умей я рисовать, обязательно нарисовал бы!

(5) Вын не поможете мне донести вещи?

Как видно из приведенных примеров, транспозиция создает синонимичные отношения. Следовательно, в примерах (1) и (2) транспонированные глагольные формы настоящего времени служат синонимами форм будущего и прошедшего времени (ср. буду ехать; возвращался, шел, увидел, белело). В примерах (3) и (4) формы императива являются синонимами форм индикатива и условного наклонения (взял и разлил; если бы я умел). А в примере (5) синтаксическая конструкция вопросительного предложения употребляется как синоним побудительного предложения (помогите мне...).

Таким образом, транспозиция как источник синонимии является ярким проявлением асимметрии знака и значения и соотносится с явлением грамматической оппозиции, что придает ей особое место в теоретической грамматике. Вопросом грамматической транспозиции занимались С. Карцевский, Е. Кржижкова, Е. Н. Шендельс, А. В. Бондарко, М. А. Шелякин и др.

Транспозиция трактуется как одна из разновидностей грамматической метафоры и ее метафорическая сущность более ярко проявляется при намеренном сопоставлении обычной и транспонированной формы (Нy, все: yхожу-ухожу, уже ушел; Ты все время в университете, а я тут убирай, мне в университеты не надо) или при использовании транспозиции в языковой игре (РЕмчукова 2000: 82-84).

Функциональное перекрещивание грамматических форм в наибольшей степени свойственно категориям эгоцентрическим (лицо, время, наклонение) и семантически сложным категориям (число), а также категориям регулярно подвергающимся преобразованию и переосмыслению (род) (Гин 1992: 13). Соответственно, личные формы, соотносящиеся не только с категорией лица, но и с категориями числа и рода, в большей степени подвергаются транспозиции. ${ }^{3}$

${ }^{3}$ Действительно, во многих языках наблюдаются транспозитивные употребления личных форм. В частности, во всех европейских литературных языках с развитой стилистической дифференциацией, личные формы могут употребляться не в своем прямом значении. Достаточно распространены «вежливое вы» и «королевское мы (royal we)» (ИСАчЕнКо 1960: 416, HEAD 1978: 166), ср.: We are not amused (Queen Victoria); Божьей поспешествующей милостью, Mьl, Николай Второй, Император и Самодержеи Всероссийский, Московский, Киевский... Следует отметить, что способы референции к участникам коммуникации варьируются в различных ситуациях и жанрах общения. Например, «авторское мы» характерно для научной 
Личные формы выражают отнесенность или неотнесенность действия к участникам речевого акта. Так, обычно считается, что формы 1 и 2 лица указывают на участников акта коммуникации, т. е. на говорящего и слушающего, а форма 3 лица - на «неучастника» акта коммуникации. ${ }^{4}$ Однако, вопреки традиционному представлению об устойчивом функциональном разграничении личных форм, они формируют очень гибкую семантическую структуру, приобретая в речи все новые смысловые компоненты. Например, в предложении Ей по-человечески говорят, а она не понимает, формы 3 л. ед. ч. (eй, она) в определенном контексте могут указывать на 2 лицо, а форма 3 л. мн. ч. (говорят) может указывать на 1 лицо.

Так как транспозиция нарушает узуальные грамматические отношения, при этом создается дополнительная оценка, эмоциональность, экспрессивность. Это связано с тем, что в транспозитивных употреблениях грамматических форм сохраняются следы их основных значений, на основе которых формируются определенные коннотации. В вышеприведенном примере происходит замена форм 1 и 2 л. на формы 3 л. А дейктическая функция формы 3 л. - обозначить неучастников коммуникации. Следовательно, называя участников коммуникации (говорящего, слушающего) формой, характерной для называния неучастника коммуникации, говорящий выражает психологическую дистанцированность от слушающего и от самого себя. Таким образом, с одной стороны он осуждает поведение слушающего, а с другой стороны, придает своему высказыванию объективность и категоричность.

Ниже подробнее будут рассмотрены транспозитивные употребления форм глагола 3 л. мн. ч. в неопределенно-личных предложениях и их синонимичные конструкции.

\section{3. Транспозиция форм 3 л. мн. ч. в неопределенно-личных предложениях и синтаксическая синонимия}

Неопределенно-личные предложения (далее НЛП) - это такие односоставные предложения, в которых действие, выраженное формами глаголасказуемого, выполняется неопределенным кругом лиц. Главный член чаще всего выражен формой 3 л. мн. ч. и намекает на подразумеваемый субъект в нулевой форме, ср.: В дверь стучат; Зазвонили в колокола; Тебе передали (передадут) книгу; У нас цену хлебу знают; Если бы меня спросили, я бы ответил согласием.

речи (как мы уже говорили; нам кажется, представляется). В публицистическом стиле наблюдается экспрессия противопоставления: «мыb - вbl», «наш - ваш» при подчеркивании двух противоположных мнений (НАм 2013: 85).

${ }^{4}$ Под личными формами подразумеваются глагольное и местоименное лицо: «Формы лица глаголов и местоимений, образующие центр поля персональности, представляют не разные грамматические категории, а одну и ту же грамматическую категорию лица» (БондАРКО 1991: 19). 
Вслед за Т. В. Булыгиной и А. Д. Шмелевым, мы обозначим форму 3 л. мн. ч. в НЛП как ØЗмн (БулыгинА-ШмЕЛЕВ 1997: 341). В отличие от ингерентно неопределенного местоимения, ØЗмн характеризуется значительным референциальным разнообразием, поскольку последнее возможно и в тех случаях, когда говорящий может идентифицировать соответствующее лицо, но представляет его в виде неопределенного лица по разным причинам. Количественный и референциальный состав мыслимого субъекта в НЛП можно наглядно продемонстрировать следующим образом (НАм 2013: 78).

а) Обобщенно-личный субъект - открытое множество:

(6) В чужой монастырь со своим уставом не ходят (пословица).

б) Неопределенно-личный субъект - открытое множество:

(7) И я не радуюсь, когда меня просят дать прочитать роман «Возвращение» (Н. Ильина: Дороги и судьбы).

в) Неопределенно-личный субъект - закрытое множество:

(8) Мне предложили сесть на старого слона, который имел такой же стаж работы на лесопилке, как я в газете (В. Овчинников: Своими глазами).

г) Определенно-личный субъект - единичный:

(9) Известие о моем предстоящем отъезде в Шанхай Катерина Ивановна приняла равнодушно. Пожала плечами: ах, вот как... Я удивилась и обиделась. Думала - ко мне привязаны, думала - во мне нуждаются, и вот я уезжаю, а ей это безразлично... (Н. Ильина: Дороги и судьбы).

Следовательно, реальный референт ØЗмн может быть не только неопределенно-личным, но может сближаться и с обобщенно-личным, и даже с определенно-личным. Такой широкий референциальный спектр ØЗмн обусловливает широкую возможность синтаксической синонимии НЛП с другими конструкциями. Однако, как было сказано выше, в транспозиции грамматических форм сохраняются следы их основных значений, на основе которых формируются определенные коннотации. Дейктическая функция формы 3 л. мн. ч. заключается в указании на неопределенное множество неучастников коммуникации. Поэтому, называя кого-либо формой 3 л. мн. ч., говорящий психологически дистанцирует его от себя. ${ }^{5}$

${ }^{5}$ Семантический компонент «дистанцированность от говорящего» обусловливает специфические употребления НЛП. В классической литературе XIX века НЛП часто описывали действия слуги, что обнаруживает точку зрения героя или автора - дворянина, дистанцирующего себя от субъекта действия - слуг, ср.: «Француз камердинер подал ему башмаки с красными каблуками, голубые бархатные штаны, розовый кафтан, шитый блестками: в передней наскоро пудрили парик, его принесли» (А. Пушкин: Арап Петра Великого). А после XX века 
Относительно этого явления Т. В. Булыгина и А. Д. Шмелев отмечают, что в НЛП референция форм ØЗмн производится по отношению к посторонним, к лицам, из числа которых исключается протагонист - тот, кто находится в фокусе эмпатии, чаще всего, говорящий (БулыгинА-Шмелев 1997: 344-345). Как нам кажется, именно "дистанцированность от говорящего», свойственная для ØЗмн, создает определенные ограничения в синонимичности НЛП.

Далее подробнее рассмотрим возможность и ограничения в формировании синонимичных отношений НЛП, исходя из референциальных свойств Øзмн.

\section{1. Синтаксическая синонимия НЛП с пассивом}

Типичной референциальностью ØЗмн является неопределенное закрытое множество. В этом случае НЛП соотносится с конкретной единичной ситуацией:

(10) Поутру пришли меня звать от имени Пугачева (А. Пушкин: Капитанская дочка).

(11) В подъезде хлопнула дверь - принесли почту с долгожданным письмом... (Н. Крыщук: Отступление).

(12) На первом курсе института нас послали однажды на рытье какого-то канала (К. Архипова: Музыка жизни).

Представляя субъект как неопределенное множество, данная транспозиция лишает референциальной определенности субъекта и тем самым понижает его коммуникативную значимость. За счет этого вместо субъекта действия на первый план выдвигается само действие или объект действия. Такой семантический сдвиг можно найти и в деагентивном пассиве. Поэтому в случае переходного глагола возможна синтаксическая синонимия НЛП с пассивом:

(11’) В подъезде хлопнула дверь - принесена почта с долгожданным письмом...

(12’) На первом курсе института мы посланы однажды на рытье какого-то канала...

НЛП стали называть действия официальных и исполнительских инстанций (НикитинА 2012: 29-30), ср.: «С января нынешнего года работникам музея не выплачивают зарплату, с апреля за долги отключили воду и электричество» (Историческая правда, 18.06.2014). Интересно отметить, что дистанцирующее отношение русских к властям ярко демонстрируется в употреблении местоимения они, указывающего на власти, ср.: «Получается, люди, которые хотят эту землю купить, совсем не бандиты? Просто бизнес, ничего личного? - они не злодеи. Они воплощение государства в той ситуации, когда оно выступает в нашей жизни как некая перемена участи. Мы ведь в повседневной речи про власти, государство, как правило, говорим безлично: они. Вот это и есть те самые они» (Известия, 16.08.2011) (см. КнязЕв 2015: 148). 
Синонимичные отношения НЛП с пассивом уже обсуждались в работах многих исследователей. В. С. Храковский определяет все предложения, в которых субъект устраняется из позиции подлежащего, как пассивные (см. ХракОвский 1974: 27), ср.: Рабочий разбил стену - Стена была разбита (рабочим) - Стену разбили. Обращая внимание на то, что безличные и неопределенно-личные предложения при переводе на другие языки обычно трансформируются в пассивные, Т. Б. Алисова настаивает на семантической общности безличных, неопределенно-личных и пассивных конструкций (АлисовА 1969: 34). ${ }^{6}$ Однако синонимичность НЛП с пассивом имеет некоторые ограничения. Во-первых, субъект в НЛП всегда является личным. Даже предложение За окном замяукали означает, что действие исполнил человек, а не животное (БулыгинА-ШмЕЛЕв 1997: 346). В отличие от НЛП в пассиве субъект не всегда бывает личным. Сравнивая предложения Его исцарапали - Его исцарапало - Он был весь исцарапан, И. А. Мельчук отмечает, что в первом примере субъект действия - лицо, во втором - стихийная сила, а третий пример не маркирован в этом отношении (МЕльчук 1974: 358). Во-вторых, как было отмечено выше, субъект в НЛП дистанцируется от говорящего или от того, кто стоит в его фокусе эмпатии. В то же время пассив не имеет такого семантического компонента. Соответственно, в случае, когда производителем действия является сам говорящий, не может возникать синонимия между НЛП и пассивом. В отличие от (13) пример (13') может интерпретироваться так, что летопись моих ранних жизненных впечатлений писал не «я», а какой-то другой человек:

(13) Летопись моих ранних жизненных впечатлений подошла к концу. Книга написана (В. Шефнер: Имя для птицы) (см. Князев 2015: 147).

(13') Летопись моих ранних жизненных впечатлений подошла к концу. Книгу написали.

Итак, синонимия НЛП с пассивом возможна при условии переходности глаголов и в случае, когда субъект в пассиве удовлетворяет требованиям личности и дистанцированности от говорящего.

\section{2. Синтаксическая синонимия НЛП с обобщенно-личными предложениями}

Ø3мн указывает на открытое множество в случае, когда в НЛП выражается общее суждение и субъект является производителем действий, происходящих типично и многократно. В этом случае, референциальность ØЗмн сближается с обобщенноличностью.

\footnotetext{
${ }^{6}$ На самом деле, категория неопределенноличности и пассив имеют точки соприкосновения в диахроническом аспекте, их происхождение и развитие тесно связаны с проблемой эргативных языков (НЕКРАСОВА 2014: 105). 
(14) Дни поздней осени бранят обыкновенно, Но мне она мила, читатель дорогой, Красою тихою, блистающей смиренно (А. Пушкин: Осень).

(15) Мешки на вид ничем не отличались от тех, в которые обычно ccbinaюm картофель (И. Антонова: Тринадцатый пират).

(16) За ученого трех неученых дают, да и то не берут (пословица).

В русском языке неопределенно-личные и обобщенно-личные референты как открытое множество могут быть выражены еще формами 1 и 2 лица. А формы 1 л. в этом значении относительно малоупотребительны. Почти все такие употребления представлены как устойчивые фразы или пословицы:

(17) Моя хата с краю, ничего не знаю (пословица).

(18) Охотно мы дарим, что нам не надобно самим (И. Крылов: Басня).

Нас больше интересует нулевая форма 2 л., которая формирует обобщенно-личные предложения как отдельный синтаксический тип. Вслед за Т. В. Булыгиной и А. Д. Шмелевым, обозначим форму 2 л. в обобщенно-личных предложениях как Øты (БулыгинА-ШмЕЛЕв 1997: 334).

(19) Бывало, под предлогом необходимой надобности, прибежишь от урока в ее комнату, усядешься и начинаешь мечтать вслух, нисколько не стесняясь ее присутствия (Л. Толстой: Детство).

(20) Сердцу не прикажешь (пословица).

А когда ØЗмн указывает на открытое множество, в принципе возможна синонимичная замена НЛП обобщенно-личными предложениями с Øты:

(15’) Мешки на вид ничем не отличались от тех, в которые обычно ccblnaemb картофель.

(16’) За ученого трех неученых даешь, да и то не берешь.

Как было отмечено, Ø3мн не имеет связи с говорящим: его собственное референциальное свойство - разграничение референта от участников коммуникации. В то же время, форма 2 лица сохраняет в себе связь с говорящим, потому что ее собственная дейктическая функция заключается в указании на участников коммуникации. ${ }^{7}$ О тесной связи Øты с говорящим Е. В. Падучева утверждает следующее: «обобщенно-личное значение 2 лица сохраняет связь с адресатным: в семантику этого употребления входит компонент 'я хочу, чтобы ты поставил себя на мое место и представил себе, что все, что я говорю про себя, происходит как бы с тобой самим'» (ПАдучеВА 1996: 212). Следовательно, специфический семантический компонент обобщенно-личных предложений с Øты - это значение личной причастности любого лица (в первую очередь, говорящего и его собеседников) к описываемой ситуации, в то

${ }^{7}$ Обратив внимание на такое различие, Е. В. Падучева обозначает ØЗмн как «третьеличный нуль», а Øты как «иллокутивный нуль» в том смысле, что она указывает на участников акта коммуникации (ПАдучЕВА 2012: 27-28). 
же время в неопределенно-личных предложениях с ØЗмн типизированные жизненные ситуации характеризуются отстраненно от говорящего как обобщение чужого, а не своего опыта. В связи с этим, Ю. П. Князев охарактеризовал предложения с ØЗмн как формулировку правила, а предложения с Øты - как его обоснование на основе личного опыта (КнязЕв 2007: 143, Князев 2015: 146).

(21) И вообще здесь, на Севере, моторы никогда не выключают - потом не заведешь (А. Гладилин: История одной компании).

(22) Это мечта практически всех руководителей: все прописали, а они там исполнили. Но, как показывает практика, чем больше прописываешь - тем больше у тебя возможности высказать человеку претензии, что он не исполнил все это, скрупулезно прописанное (Эксперт, 17.12.2012).

Итак, из разных референциальных свойств форм 2 и 3 л. вытекает ограничение в синонимичности НЛП с обобщенно-личными предложениями.

Поэтому синонимичная замена неестественна в случае, когда подчеркнута дистанцированность субъекта от говорящего. Например, в примере (14) мнение других людей противопоставлено мнению говорящего, так что из множества людей, подразумевающихся в качестве денотата нулевого субъекта, исключается говорящий (ПАдучевА 2012: 33). Поэтому в данном случае неестественна синонимичная замена формой 2 л., которая включает и самого говорящего в состав потенциальных субъектов действия:

$(14)^{\prime}$ Дни поздней осени бранишь обыкновенно, Но мне она мила, читатель дорогой, Красою тихою, блистающей смиренно.

\section{3. Синтаксическая синонимия НЛП с определенно-личными предложениями}

ØЗмн возможно и в тех случаях, когда говорящий может идентифицировать соответствующее лицо, но представляет его в виде неопределенного лица либо для воспроизведения своего состояния неведения, либо потому, что не считает нужным конкретизировать субъект.

(23) Она украла у меня золотую цепочку! - крикнула женщина в зал. - Наша невестка! Или ее гости так называемые! Приезжаем с участка, а цепки нет! - Ура! - бодро откликнулась ведущая. - Украли и правильно сделали! (Л. Петрушевская: Маленькая волшебница).

(24) Этой тирадой я думала Катерину Ивановну обрадовать, случилось иначе. Слушали меня холодно, глядели отчужденно, я стала путаться в словах, наконец, замолчала растерянно, и была долгая пауза (Н. Ильина: Страницы из семейного альбома).

В этих примерах референт ØЗмн - единичное определенное лицо: она, Катерина Иванона. Возможно конкретное их называние: 
(23’) Она украла у меня золотую цепочку! - крикнула женщина в зал. - Наша невестка! Или ее гости так называемые! Приезжаем с участка, а цепки нет! - Ура! - бодро откликнулась ведущая. - Она украла и правильно сделала!

(24’) Этой тирадой я думала Катерину Ивановну обрадовать, случилось иначе. Катерина Ивановна слушала меня холодно, глядела отчужденно...

А какие при этом возникают семантические различия? Комментируя Øзмн в определенно-личном значении, Т. В. Булыгина и А. Д. Шмелев отмечают, что такая транспозиция указывает на отчуждение, объективизацию и взгляд со стороны на субъекта и всю сцену (БулыгИнА-ШмЕЛЕВ 1997: 342).

(25) Он едет, лишь вошел... Она навстречу. Как сурова! Его не видит, с ним ни слова... У! Как теперь окружена Крещенским холодом она! (А. Пушкин: Евгений Онегин).

Сходную мысль высказала Е. Н. Никитина. По ее мнению, наложение формальной множественности в неопределенно-личной конструкции и семантической определенности агенса становится основанием для формирования семантики отчужденности между субъектом диктума (неназванным агенсом) и субъектом модуса (тем, кто находится в фокусе эмпатии) и для передачи личностных конфликтов. В примере (26) посредством НЛП А. Чехов выстраивает конфликтную субъектную перспективу, соединяющую субъекта внутренней речи Лаевского и агенса фон Корена (НикитинА 2012: 31-32):

(26) Убъют ли его завтра утром, или посмеются над ним, то есть оставят ему эту жизнь, он все равно погиб (А. Чехов: Дуэль).

Мы считаем, что в такой интерпретации есть доля правды. Но, с другой стороны, поскольку здесь третье лицо ед. ч. заменяется третьим лицом мн. ч. и меняется лишь числовая форма, должна быть иная мотивация, чем отчуждение или объективизация. На самом деле, подобная числовая транспозиция возможна и в контексте, которому не свойственно отчуждение:

(27) Она навстречу. Как мила! Встречает меня, усаживает за стол, угощает.

(27’) Она навстречу. Как мила! Встречают меня, усаживают за стол, угощчют.

Итак, мы считаем, что здесь транспозиция Øзмн призвана подчеркнуть интенсивность действия или проявления признака. Так, в примерах (24) и (25), называя действие Катерины и Татьяны формами 3 л. мн. ч., говорящий преувеличивает холодность их поведения и тем самым подчеркивает дистанцированность героев от говорящего или от протагониста, чью точку зрения разделяет говорящий. 
Интересно отметить, что ØЗмн может указывать также на говорящего. В большинстве таких случаев, высказывания включают глаголы речи и напрямую обращены к адресату:

(28) Тебе говорят, надень пальто, да тебе добра желают, пойми!

(29) Никто не гонит тебя, братец, тебя просят, тебе говорят.

С учетом дистанцированности от говорящего, такие употребления Øзмн могут показаться парадоксальными. Однако они не являются контрпримерами, так как здесь транспозиция ØЗмн указывает на то, что говорящий отказывается от своей выделенной позиции, скрывается за неопределенным множеством, и тем самым создается эффект объективности и категоричности в высказывании.

\section{4. Выводы}

Транспозиция грамматических форм представляет собой источник семантической деривации и механизм синтаксической синонимии. С этой точки зрения мы рассмотрели синтаксическую синонимию неопределенно-личных предложений с формой 3 л. мн. ч. (ØЗмн). Ø3мн характеризуется значительным референциальным разнообразием. Референт Øзмн может быть не только неопределенно-личным, но может сближаться и с определенноличным и обобщенно-личным. В соответствии с референциальным варьированием мыслимого субъекта, НЛП вступают в синонимичные отношения с определенно-личными, деагентивно пассивными и обобщенно-личными предложениями.

При этом в транспозитивных употреблениях грамматических форм сохраняются следы их основных значений, на основе которых формируются определенные коннотации. В случае ØЗмн возникает дистанцированность от говорящего, так как формам 3 л. мн. ч. свойственна функция указания на неопределенное множество лиц-неучастников коммуникации. Следовательно, называя субъект какого-то действия формой 3 л. мн. ч., говорящий исключает себя из множества людей, подразумевающихся в качестве денотата нулевого субъекта и излагает ситуацию как бы извне, со стороны посторонних. Такая коннотация создает определенные ограничения в синонимичных отношениях НЛП с другими конструкциями.

\section{Литература}

АлисовА 1969 = АлисовА Т. Б. Семантико-коммуникативный субстрат безличных предложений. В кн.: АрутюновА Н. Д. (ред.) Инвариантные синтаксические значения и структура предложения. Москва, 1969. 27-36.

БондАРко 1991 = БондАРко А. В. Семантика лица. В кн.: БондАРко А. В. (ред.) Теория функииональной грамматики. Персональность. Залоговость. Санкт-Петербург, 1991. 5-40. 
БУЛЫГИНА-ШМЕЛЕВ 1997 = БУЛЫГИНА Т. В., ШМЕЛЕВ А. Д. ЯЗыковая концептуализация мира (на материале русской грамматики). Москва, 1997.

ГАЛКИНА-ФЕДОРУК 1958 = ГАЛКИНА-ФЕДОРУК Е. М. Синонимы в русском языке. Москва, 1958.

Гин 1992 = Гин Я. И. Поэтика грамматического рода. Санкт-Петербург, 1992.

ЗолотовА 1973 = ЗолотовА Г. А. Очерк функционального синтаксиса русского языка. Москва, 1973.

ИСАЧЕНКО 1960 = ИСАЧЕНКО А. В. Грамматический строй русского языка в сопоставлении со словачким. Морфология. Ч. 1-2. Братислава, 1960.

КнязЕВ 2007 = КнязЕВ Ю. П. Грамматическая семантика. Москва, 2007.

КнязЕВ 2015 = КнязЕВ Ю. П. Неопределенно-личные предложения в русском языке на фоне других конструкций с неназванным субъектом. В кн.: $K$ 150-летию кафедры общего языкознания СПбГУ. Санкт-Петербург, 2015. 140-150.

ЛЭС 1990 = Лингвистический энииклопедический словарь. Москва, 1990.

МАРОЕВИч 1993 = МАРОЕВич Р. Неопределенно-личные предложения в русском языке и их сербские эквиваленты. Вопросы языкознания 1993/2: 96-106.

МЕльчук 1974 = Мельчук И. А. О синтаксическом нуле. В кн.: Типология nассивных конструкиий. Диатезы и залоги. Ленинград, 1974. 343-361.

НАм 2013 = НАм Хе Хён: Анализ неопределенно-личныХ предложений в русском языке как диатетического явления. Исследование по славянским языкам 2013/1: 71-88.

НЕКРАСОВА 2014 = НЕКРАСОВА И. М. Конструкции «без агенса»: опыт сопоставительного исследования семантической структуры. Вестник Пермского университета. Российская и зарубежная филология 2014/4: 99-107.

НикитинА 2012 = НикитинА Е. Н. Категория субъекта и неопределенно-личные предложения. Вестник Московского университета. Серия 9. Филология 2012/4: 25-34.

ПАДУчЕВА 1996 = ПАДУчЕВА Е. В. Семантические исследования. Семантика времени и вида в русском языке. Семантика нарратива. Москва, 1996.

ПАДУчЕВА 2012 = ПАДУчЕВА Е. В. Неопределенно-личное предложение и его подразумеваемый субъект. Вопросы языкознания 2012/1: 27-41.

ПЕшковский 1930 = ПЕшковский А. М. Принципь и приемы стилистического анализа и оизенки художественной прозы. Москва, 1930.

РЕмчуковА 2000 = РЕмчуковА Е. Н. Морфологическая транспозиция как тип функционального варьирования грамматической формы. В кн.: БондАРко А. В., ШуБик С. А. (ред.) Проблемь функциональной грамматики. Категории морфологии и синтаксиса в выскказывании. Санкт-Петербург, 2000. 79-90.

СосСюр 1977 = Соссюр Ф. Труды по языкознанию. Москва, 1977.

ХРАКОВСКИЙ 1974 = ХРАКОВСКИЙ В. С. Пассивные конструкции. В кн.: Типология пассивных конструкиий. Диатезы и залоги. Ленинград, 1974. 5-45.

ЧуЛАНОВА 2009 = ЧулАНОВА А. Динамическая синонимия сложноподчиненных предложений и сверхфразовых единств в современном русском языке. АКД. Ростовна-Дону, 2009.

HEAD 1978 = HEAD B. Respect degrees in pronominal reference. In: GREENBERG J. (ed.) Universals of Human Language 3. World Structure. Stanford, 1978. 151-211.

NAGY 2009 = NAGY A. К проблеме классификации грамматической синонимии: параллели - варианты - синонимы. Studia Russica XXIII. Budapest, 2009. 314-317.

SieWERSKA-PAPASTATHi 2011 = SiewersKa A., PAPAStATHi M. Towards a typology of third person impersonals. Linguistics 49 (2011): 575-610. 